\title{
5 Future Trends (I): Pedagogical Conversational Agents
}

\subsection{Introduction}

It can be said that natural language is the most natural way for humans to interact with computers, because humans interact using natural language with other humans. That way, the users are not limited to a set of keywords, or options from a menu, but they can enter sentences in natural language that are understood by the computer, which, in turn, generates more sentences in natural language (Kelley, 1984; Zhou, 2007).

Natural Language Processing techniques (Mitkov, 2003; Indurkhya \& Damerau, 2010) can be used to improve human-computer interaction. In particular, natural language interaction has been widely used to support database query, question answering, command and control, and other types of information systems (Zhou, 2007).

In the domain of education, natural language interfaces provide a natural method for interacting with the students (Crowley et al. 2005). In particular, using Pedagogical Conversational Agents (PCAs), that is, "lifelike autonomous characters that cohabit the learning environment creating a rich interface face-to-face with the student" (Johnson et al. 2000), has been gaining influence in the last decades, although it is still under research. Figure 5.1 shows a sample of Shamael, an agent that was developed in 2010 to encourage children to do their homework (Pérez-Marín \& Pascual-Nieto, 2012).

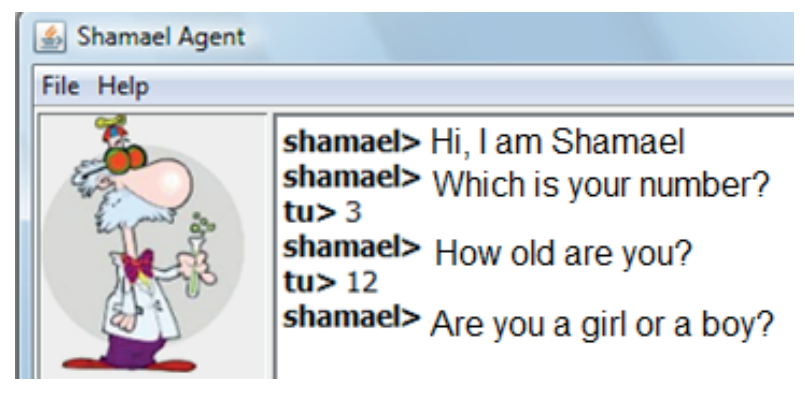

Figure 5.1: Shamael

Lester et al. (1997) discovered the Persona effect, according to which, just the presence of an interactive agent in an educational computer environment has a positive influence on the students' perception of the learning experience. Moreover, Yee and Bailenson (2007) discovered the Proteus effect, according to which students are motivated to achieve the features of the agents to become more like them; and, Chase et al. (2009) discovered the Protégé effect, according to which students can make greater efforts to teach their agents than to study on their own.

(c) BY-NC-ND () 2014 Diana Pérez Marín

This work is licensed under the Creative Commons Attribution-NonCommercial-NoDerivs 3.0 License. 
PCAs can assume several roles, depending on the pedagogical goal they pursue: they can be teachers, students, companions, tutors, coaches, etc. In this chapter, the focus is on the roles of teachers, students and companions as this offers a global view of the possibilities that PCAs can offer to education. For instance, Figure 5.2 shows a sample dialogue that was generated between the agent Fisca (Pérez-Marín and Boza, 2013), taking the role of teacher, and a student called Iván when practising Physics. Figure 5.3 shows a longer sample dialogue between Lingu and a Primary Education student practising basic morphological and syntactical analysis (Gallo \& Pérez-Marín, 2011). All these agents have been developed by my students at the Universidad Rey Juan Carlos.

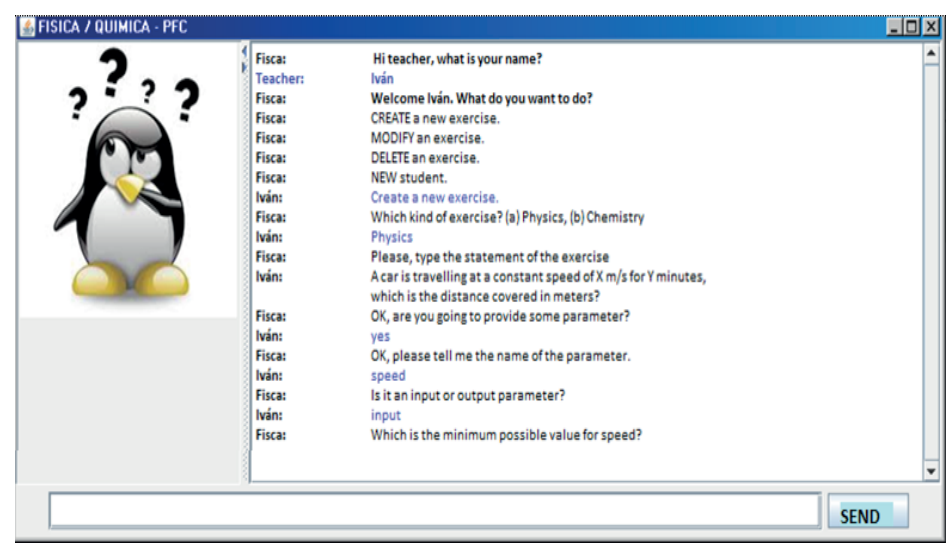

Figure 5.2: Fisca

$\begin{array}{ll}\text { Agent: } & \text { Hello, Student. How are you? } \\ \text { Student: } & \text { Very well, thank you. } \\ \text { Agent: } & \text { OK, let's start with the analysis of the sentence: "She lives". } \\ \text { Agent: } & \text { Which part-of-speech is the word "She"? } \\ \text { Student: } & \text { Pronoun. } \\ \text { Agent: } & \text { Very good, and which gender is it? } \\ \text { Student: } & \text { Masculine. } \\ \text { Agent: } & \text { Oh! I am afraid that the gender is feminine. } \\ \text { Agent: } & \text { And, which number is it? } \\ \text { Student: } & \text { Singular. } \\ \text { Agent: } & \text { Very good, and which part-of-speech is the word "lives"? } \\ \text { Student: } & \text { Noun. } \\ \text { Agent: } & \text { Oh! I am afraid that the part-of-speech is verb. } \\ \text { Agent: } & \text { And, in which tense is it? } \\ \text { Student: } & \text { Present. } \\ \text { Agent: } & \text { And, in which number is it? } \\ \text { Student: } & \text { Singular. } \\ \text { Agent: } & \text { And, in which person is it? } \\ \text { Student: } & \text { Second. } \\ \text { Agent: } & \text { Oh! I am afraid that the person is third. } \\ \text { Agent: } & \text { OK, do you want to continue with another sentence? } \\ \text { Student: } & \text { No, it is enough for today. } \\ \text { Agent: } & \text { OK, goodbye. }\end{array}$

Figure 5.3: Lingu 
Section 5.2 presents more agents with some relevant pedagogical feature to study (i.e. Learning by Teaching, Learning by Doing, and Learning by Explaining paradigms). In addition, some are representatives of a certain domain or possibility, such as empathy, virtual worlds, 3D visualization, etc. The agents have been grouped according to the three main roles previously stated: teacher, student or companion. Nevertheless, it is important to highlight that there are many more agents, and surely many more still to come! So, please, continue reading to learn more about these agents. In Section 5.3 there's an example agent, with a look at how to interact with it. Section 5.4 presents a taxonomy to help you identify which agent could be most useful for you, based on several criteria. Finally, solve the exercises in 5.5 to practise the content of this chapter.

\subsection{Overview of PCAs}

\subsubsection{PCAs Taking the Role of Teachers}

Herman the Bug (Lester et al. 1997) is an agent in the shape of an insect, designed to teach Biology to children. Herman always starts the conversation, but it does not have any type of animation or affective possibilities. It was designed to be used with a computer in English and could be used with different combinations of gestures and verbal advice. Figure 5.4 shows a snapshot of one of the modes of the agent.

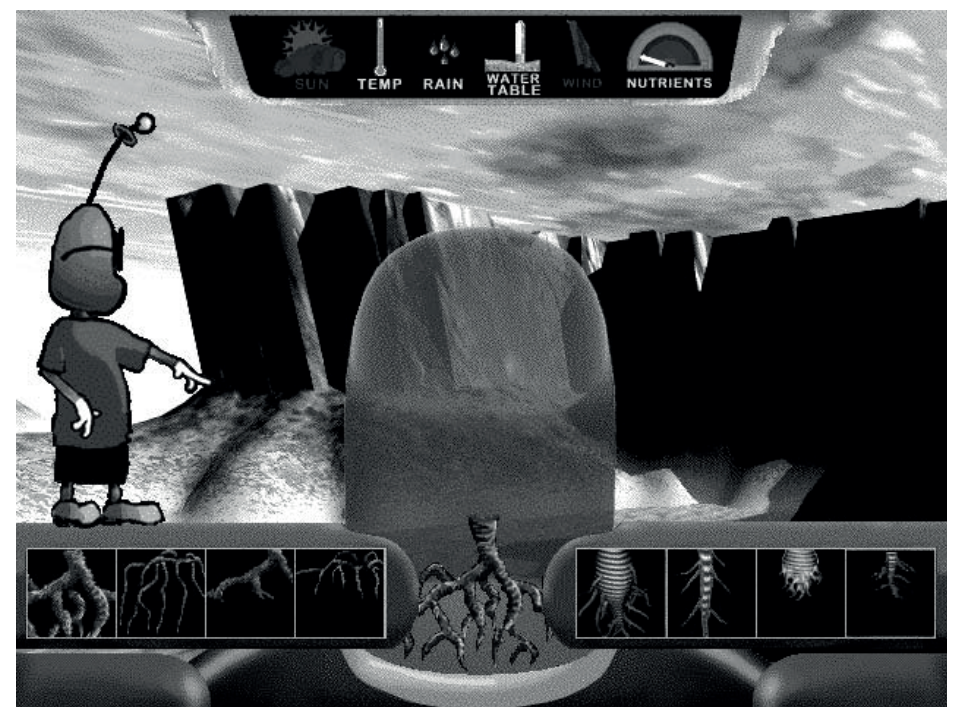

Figure 5.4: Herman the Bug (Lester et al. 1997) 
Steve (Rickel and Johnson, 1999) is an agent with human shape to teach navy training to adults in a 3D virtual world. Steve has a mixed-interaction dialogue modality, that is, it is possible both for Steve and the student to follow the turn of conversation. This agent can provide some basic emotional support with full body 3D animation. It has been designed to be used with a computer in English. Figure 5.5 shows a snapshot of Steve.

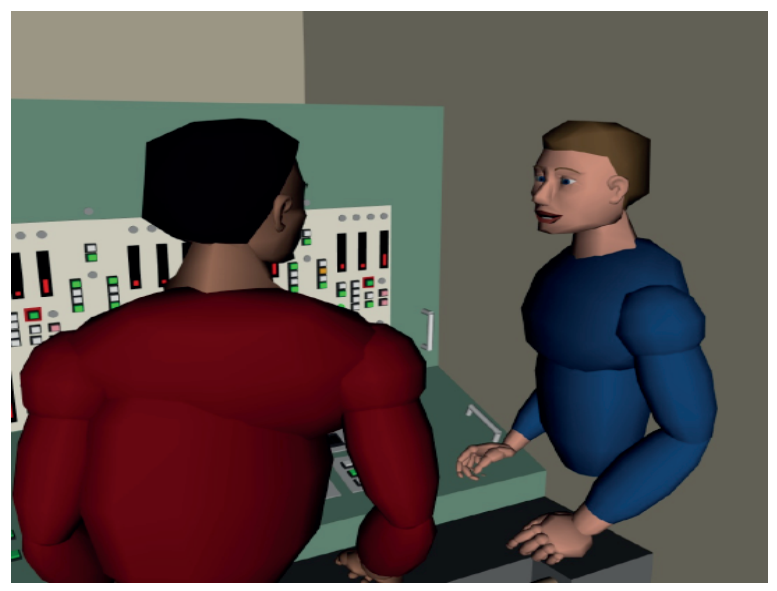

Figure 5.5: Steve (Rickel and Johnson, 1999)

Guilly (Nunes et al. 2002) is an agent with a worm shaped body with basic animation to teach children how to do the urban garbage selection. Guilly starts the conversation and guides it without allowing the student to change the turns. It has been designed to be used with a computer in English. Figure 5.6 shows a snapshot of Guilly.

An interesting feature explored in Guilly is the use of a metaphor to represent student performance. In particular, there is a tree on the left of the screen to show how well the student is separating the garbage. The tree represents the whole environment, and the greener it is, the better the student is doing the job.

Sam (Ryokai et al. 2003) is an agent with a human child shape. It has been designed to be projected on a wall behind a castle. This is because Sam's goal is to teach students to tell stories, and he uses the castle as the backdrop for the story. The conversation is always driven by Sam, and it is in English. The experiments carried out have shown that children interacting with Sam are able to improve their storytelling skill. Figure 5.7 shows a snapshot of Sam.

Autotutor (Graesser et al. 2008) is an agent with human shape designed to teach qualitative domains to children and adults. Autotutor is able to follow a mixeddialogue interaction, in which both the agent and the student can change the turn of 
the conversation. It has a human face able to talk, to show empathy with the student and to support 3D animation. Autotutor has been designed to be used with a computer in English. The experiments carried out with Autotutor show that students are able to increase their score in their final exam when using this agent to study. Figure 5.8 shows a snapshot of Autotutor.

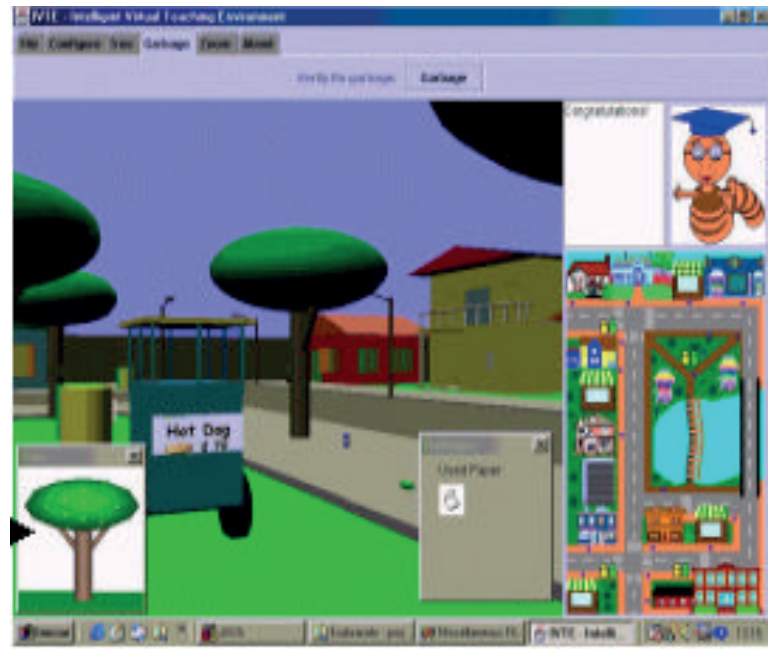

Figure 5.6: Guilly (Nunes et al. 2002)

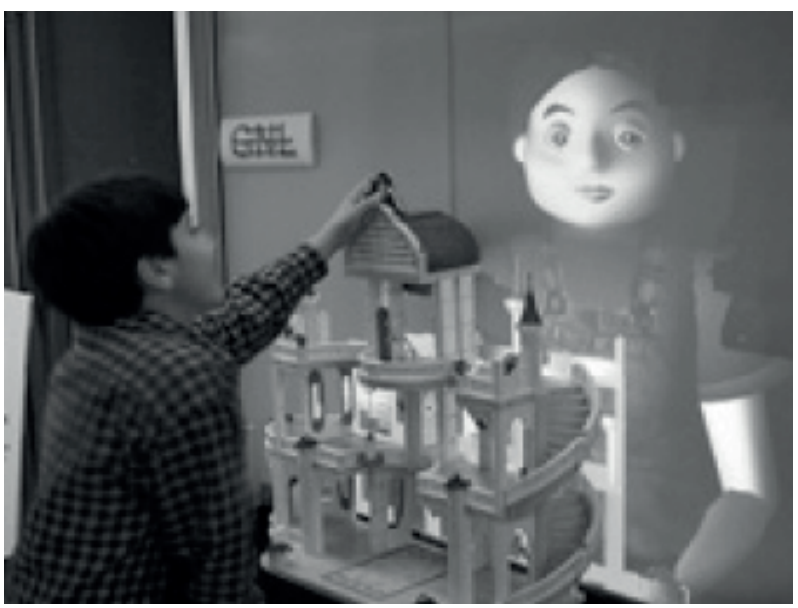

Figure 5.7: Sam (Ryokai et al. 2003) 


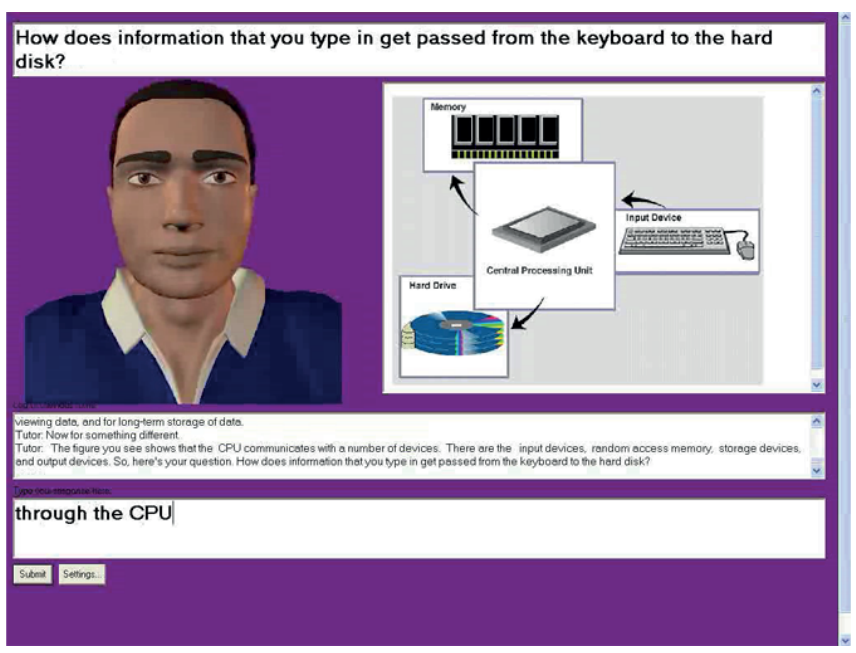

Figure 5.8: Autotutor (Graesser et al. 2008)

Baldi (Massaro et al. 2005) is an agent with a human face able to talk. It serves as a language training tutor for English children with some kind of hearing impairment or adults learning English as second language. The conversation is driven by the student who clicks on an object to be pronounced by Baldi. The agent has been designed to be used with a computer or a PDA. According to its authors, Baldi is able to achieve satisfactory results to accomplish his goal, provided that the conversation is driven by the student. Figure 5.9 shows a snapshot of Baldi.

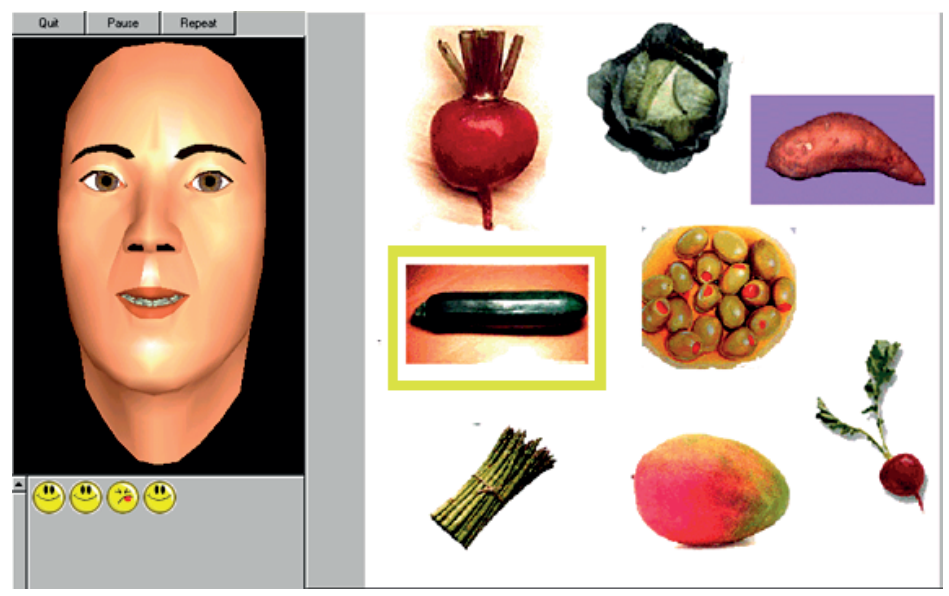

Figure 5.9: Baldi (Massaro et al. 2005) 
Willow (Pérez-Marín, 2007) is an agent which can be represented by both human and animal shapes to teach conceptual domains to children and adults. The conversation is driven by the agent, which has been designed to be used on a computer in Spanish or in English. Figure 5.10 shows a snapshot of Willow. It will be explained in more detail in Section 5.3.

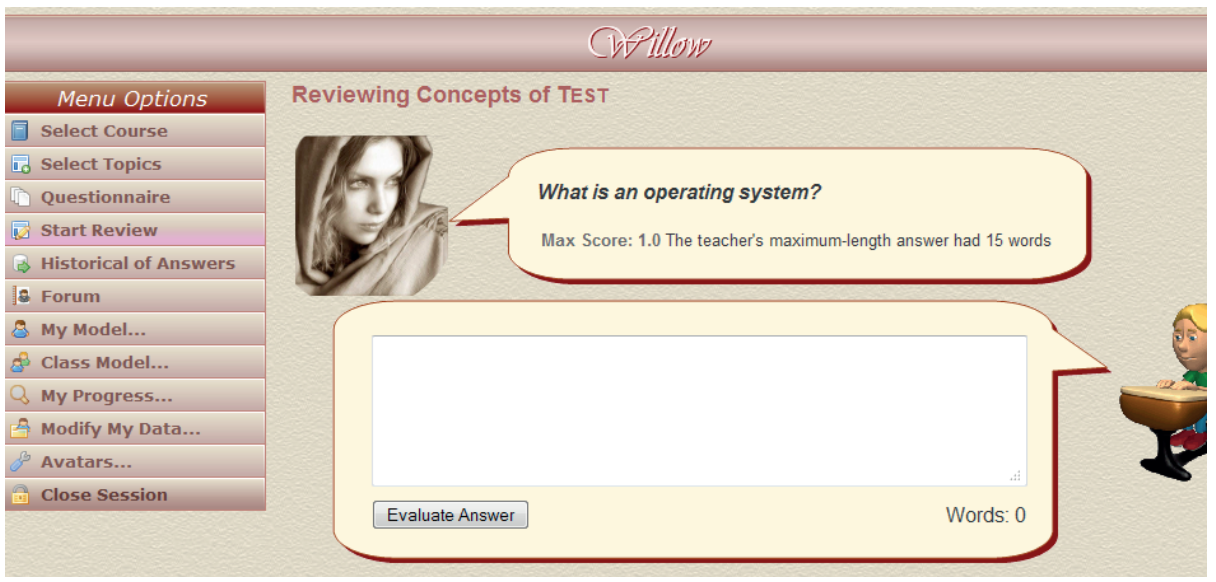

Figure 5.10: Willow

\subsubsection{PCAs Taking the Role of Students}

Betty (Biswas et al. 2009; Segedy et al. 2013) is an agent with human shape. In particular, she is represented as a little girl, who wants to learn about science. In this case, the agent is based on the Learning by teaching paradigm. Therefore, Betty waits until children teach her, and she answers the questions asked by the children to check whether she has understood the lessons.

Therefore, the conversation is driven by the students, and it is supported by the use of a concept map. Betty has been designed to be used with a computer with graphics and sound animation in English. In the case that the information provided to Betty is incorrect, another supervisor agent called Mr. Davis is in charge of indicating that there is something wrong. Figure 5.11 shows a snapshot of Betty and Mr. Davis. 


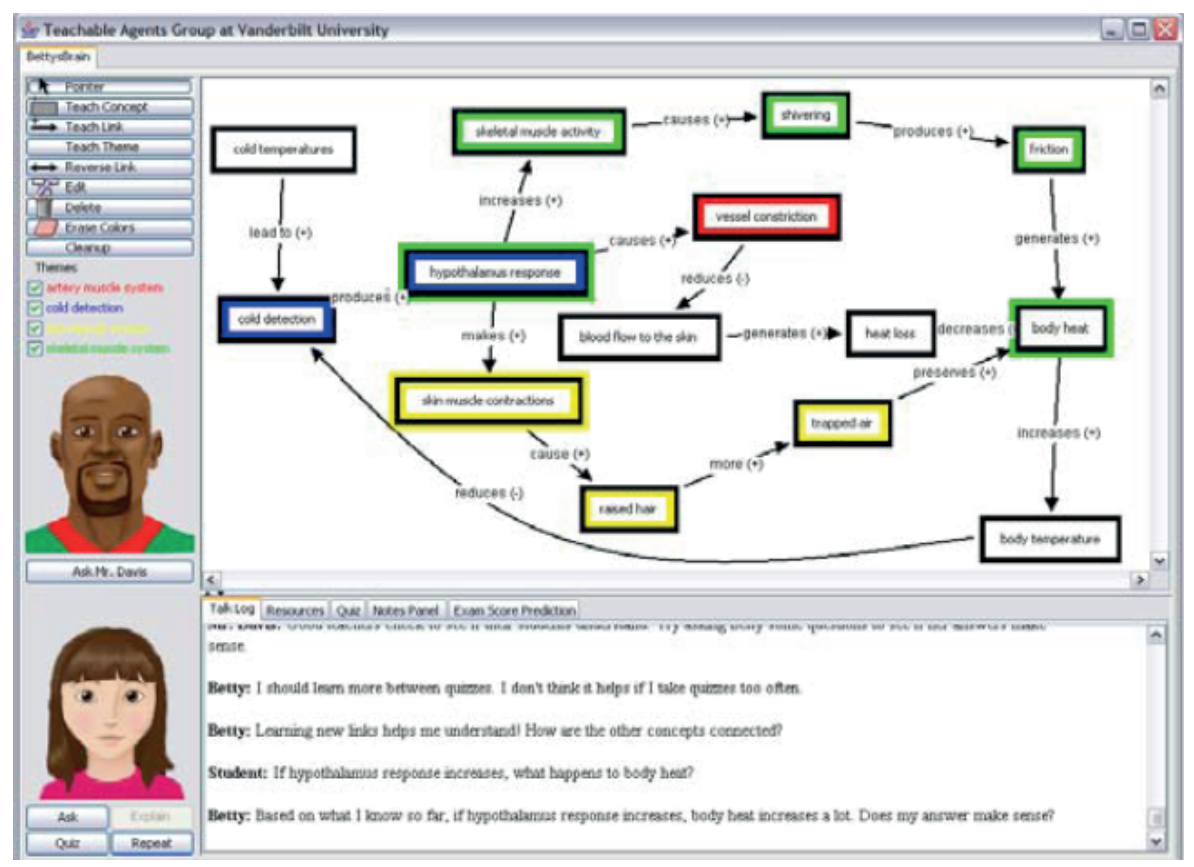

Figure 5.11: Betty (Biswas et al. 2009)

Agents in Active Worlds (Holmes, 2007) are able to interact with the students, waiting for their explanations, following the Learning by explaining paradigm. According to the author, generating explanations encourages students to learn new content with deeper understanding and to monitor their own comprehension more effectively. The domain was river ecosystem concepts. The results of the experiment demonstrated that software agents have a positive impact as learning helpers in a virtual world environment. Figure 5.12 shows a sample of Erin and Jeffh talking in Active Worlds.

Mike's teachable agent (Pareto et al. 2012) is able to learn from children in a collaborative and competitive way. Students play with Mike and other students in the Maths domain. According to Mike's creators, students using Mike were able to significantly increase their Math comprehension scores and they felt more confident in explaining math. The collaborative and competitive activities are reported as able to foster student motivation when using the agent. Figure 5.13 shows a sample of Mike. 


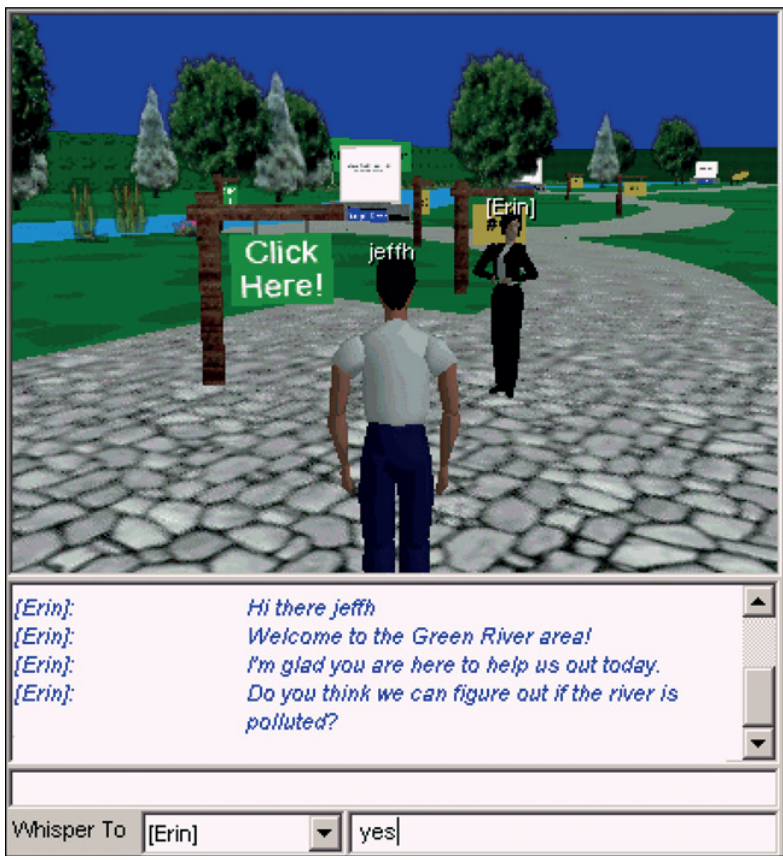

Figure 5.12: Agents in Active Worlds (Holmes, 2007)

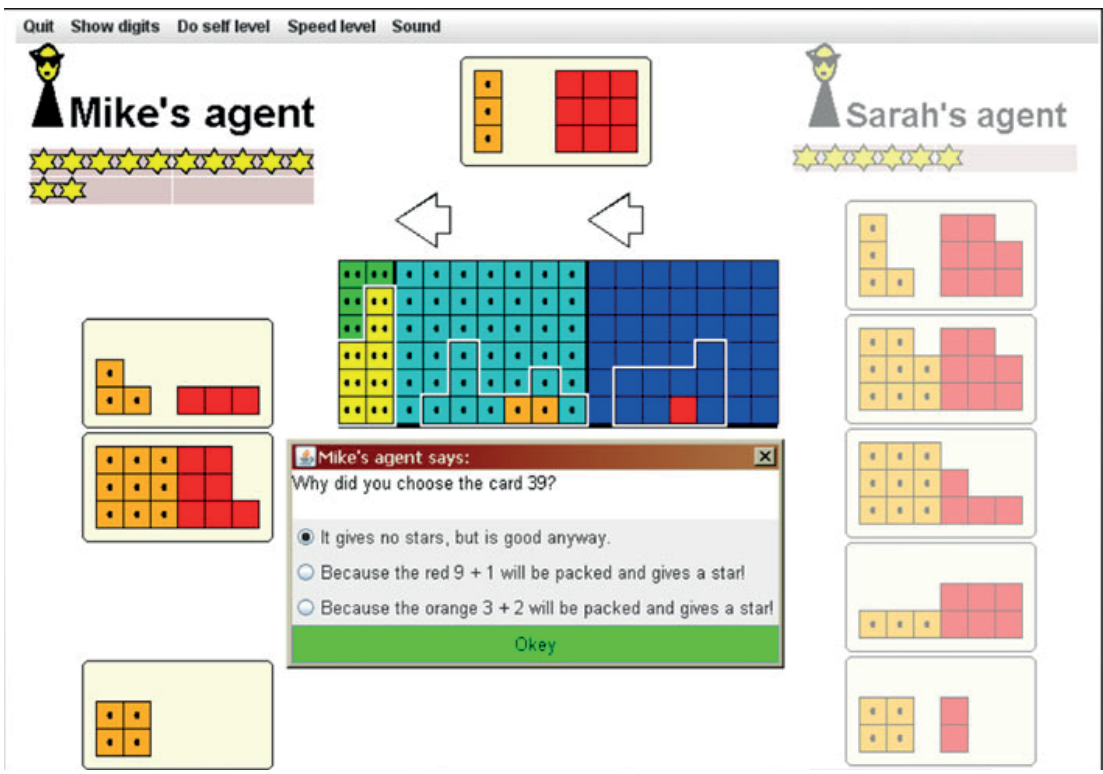

Figure 5.13: Mike’s teachable agent (Pareto et al., 2012) 


\subsubsection{PCAs Taking the Role of Companions}

All agents presented here assume the role of companions following the Learning by Doing paradigm. That is, the agent is not designed to teach or to act as a student, but it serves to provide emotional support to motivate the students to keep studying and to carry out certain tasks in the environment. In these cases, the agent-student natural language conversation is usually less important, even replaced by gestures or static menu-based choices. On the other hand, the 3D animated graphical environments are richer and more effort is usually placed on trying to empathize with the student's feelings.

The SBEL agents (Reategui et al. 2007) have human shapes to teach Brazilian Portuguese to children and adults. The conversation is driven by the agents who train the student to speak correctly in several different situations. The agents have been designed to be used with a computer. Figure 5.14 shows a snapshot of one of the SBEL agents.

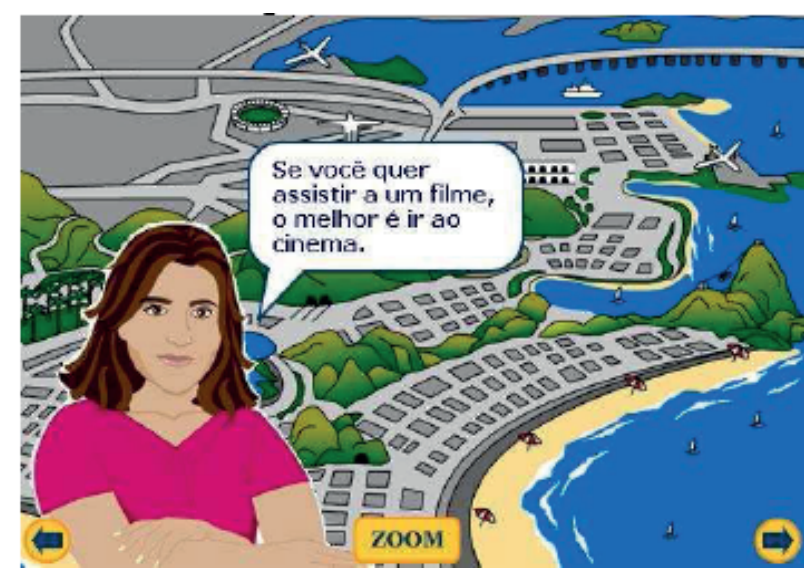

Figure 5.14: SBEL agents (Reategui et al. 2007)

The Crystal Island agents (Robinson et al. 2009) have a full animated body and interact with other agents and students in the Crystal Island immersive learning environment. They aim to help students (children and adults) carry out certain tasks. There is a mixed-initiative dialogue and the agents have 3D graphics and sound animation. They have been designed to be used with a computer in English. One of the hypotheses of this research is that dealing with the student's feelings will increase the performance of the student, instead of serving as a distracting factor. The published results seem to validate that hypothesis. However, this is still being researched. Figure 5.15 shows a snapshot of the environment and the agents. 


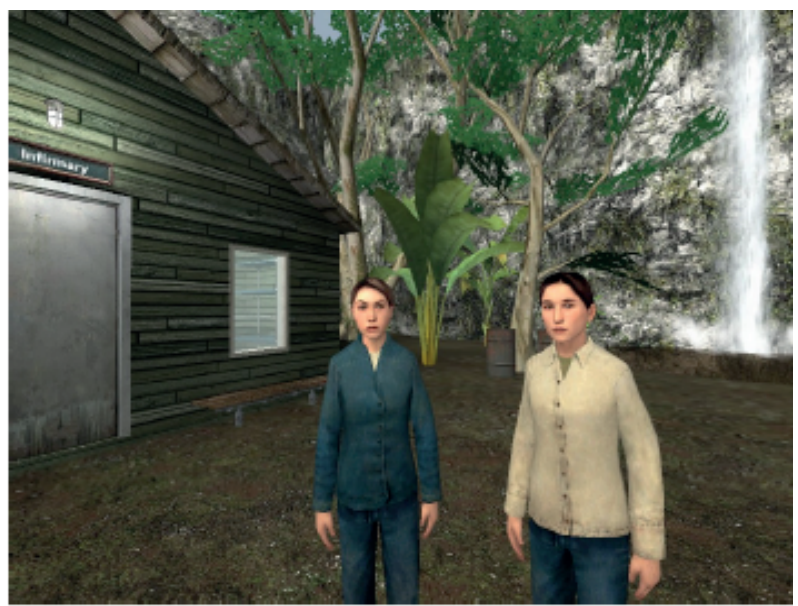

Figure 5.15: Crystal Island agents (Robinson et al. 2009)

Jake and Jane (Arroyo et al. 2009) are two human-form agents intended to provide emotional support to Math students. Jake and Jane are exactly the same except for their gender, and they support mixed-initiative dialogue with 3D graphics, sound and the taxonomy of emotions provided by Ekman (1999). The agents have been designed to be used with a computer in English. Figure 5.16 shows a snapshot of the environment and the agents.

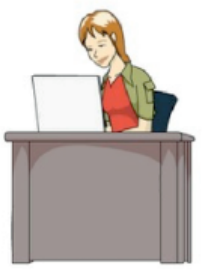

Confident

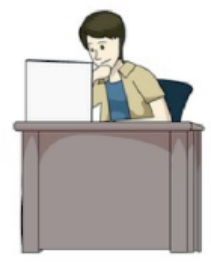

Focused

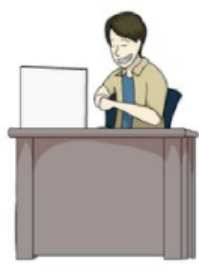

Excited

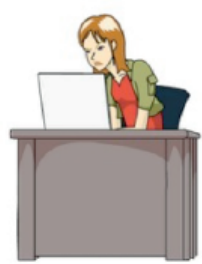

Frustrated

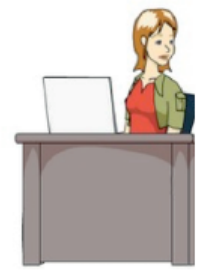

Bored

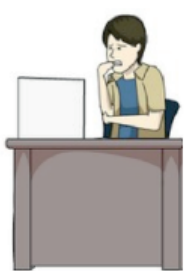

Anxious

Figure 5.16: Jake and Jane agents (Arroyo et al. 2009) 
As was the case with the Crystal Island agents, one of the goals here is to try to empathize with the student, for example by changing the gender of the agent. According to the authors, this may have an impact, particularly on the female students who, when interacting with the male agent, had better performance. However, that hypothesis is still being actively researched.

MyPet (Chen et al. 2009) is an agent with an animated animal (dog or cat) form, it is used to motivate Chinese children to study. The conversation is driven by the agent. MyPet has been designed to be used with a computer or PDA in Chinese. Figure 5.17 shows a snapshot of MyPet.

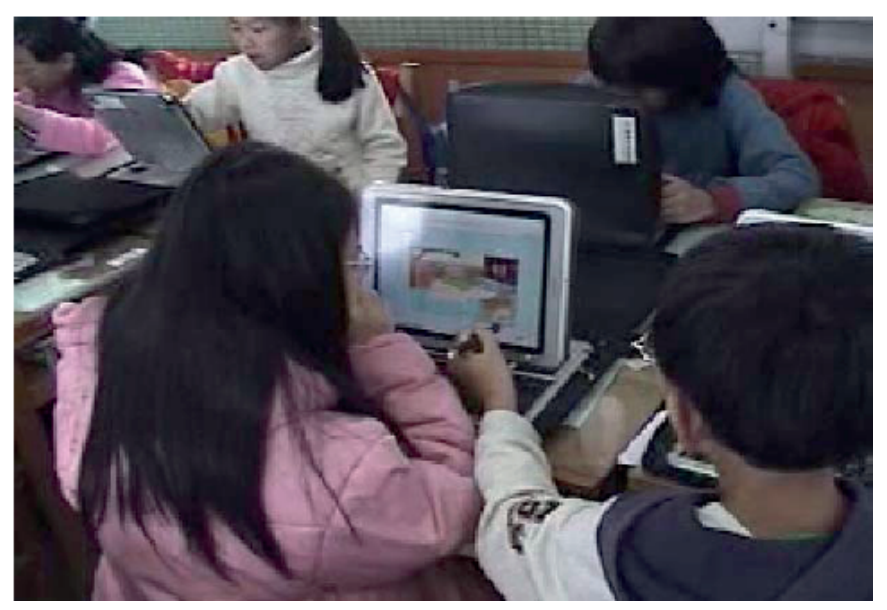

Figure 5.17: MyPet (Chen et al. 2009)

One of the hypotheses of the researchers of MyPet is that if students believe that their failure is due to lack of effort, they will keep working, as it is possible to make a greater effort and pass the course. On the other hand, if students believe that their failure is due to lack of capacity, they will stop working. In order to test the hypothesis, MyPet shows an energy bar that represents the effort made by each student to study as calculated by the agent. According to the authors, in the experiments that they have performed, they have found evidence to support their hypothesis. On the other hand, the authors have not found evidence of any learning improvement. This issue is still being investigated.

Finally, the BILAT agents (Hays et al. 2009) are actors in a training game, whose goal is to improve the negotiation skills of the adult players. The agents support mixed-initiative dialogue, although it is not a natural language dialogue, but is based on menus with a list of possible sentences to choose from. The BILAT agents have been designed to be used with a computer in English. Figure 5.18 shows a snapshot of the BILAT environment. 


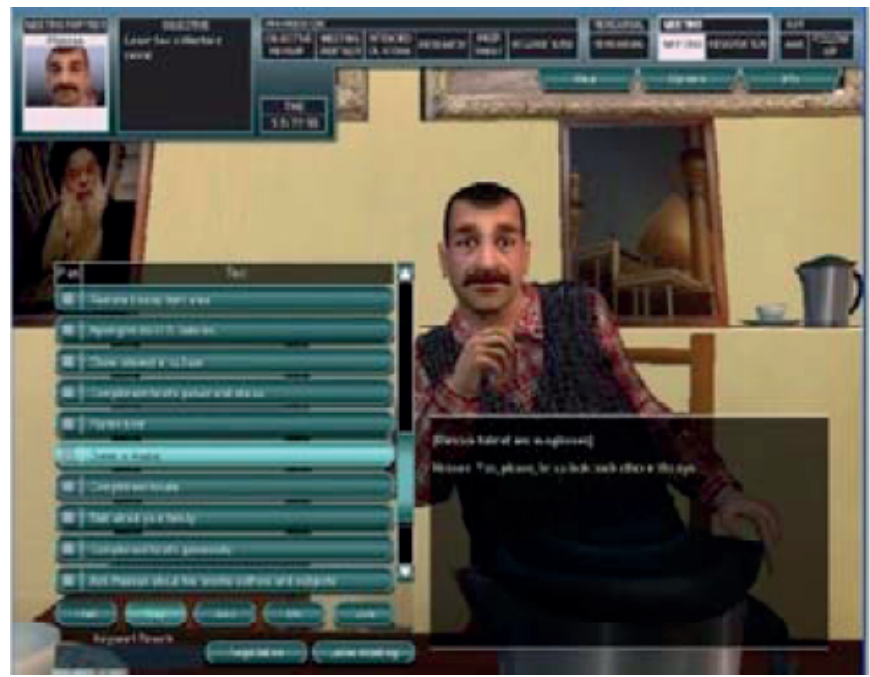

Figure 5.18: BILAT agents

The BILAT environment is created in the research line of Serious Games. That is, to provide the student with a full animated graphics visual environment so that they accomplish certain tasks as they are playing the game. The researchers have reported evidence of an increase in the training skill of the students who have used the environment.

\subsection{Let's Practise With the Willow Agent}

Let's practise with an agent. In this case, I have chosen Willow (Pérez-Marín, 2007), see Figure 5.10, because I can give you free access to the agent. Willow is integrated into a b-learning (Graham, 2005) web system able to support students when studying for their final exams. The whole system follows a metaphor dialog in which both the agent and the student are represented by avatars associated with a text bubble in which the sentences uttered by each of them appear when the turn changes. Moreover, Willow is able to adapt the dialogue to the level of difficulty to be managed by each student.

Initially, all students are asked to fill in a small form to give their personal information (name, age, sex), and they are then assigned to the novice level. The questions in Willow are classified by the instructors as easy, average or difficult. Instructors also determine the percentage of questions at each level of difficulty that need to be passed in order to move up to a higher level of difficulty. Likewise for the percentage of questions that need to be failed to move down to a lower level of difficulty. 
When students answer a question, they go to a feedback page like the one shown in Figure 5.19. The question is at the top, together with the student's answer. The automatic evaluation is in the middle, the self-assessment possibility below, and finally the correct answers provided by the instructor at the bottom. After the evaluation screen, the student can choose to go to a new question, to change the automatic assessment for a different score (self-assessment), or just to read the correct answers provided for that question and close the application.

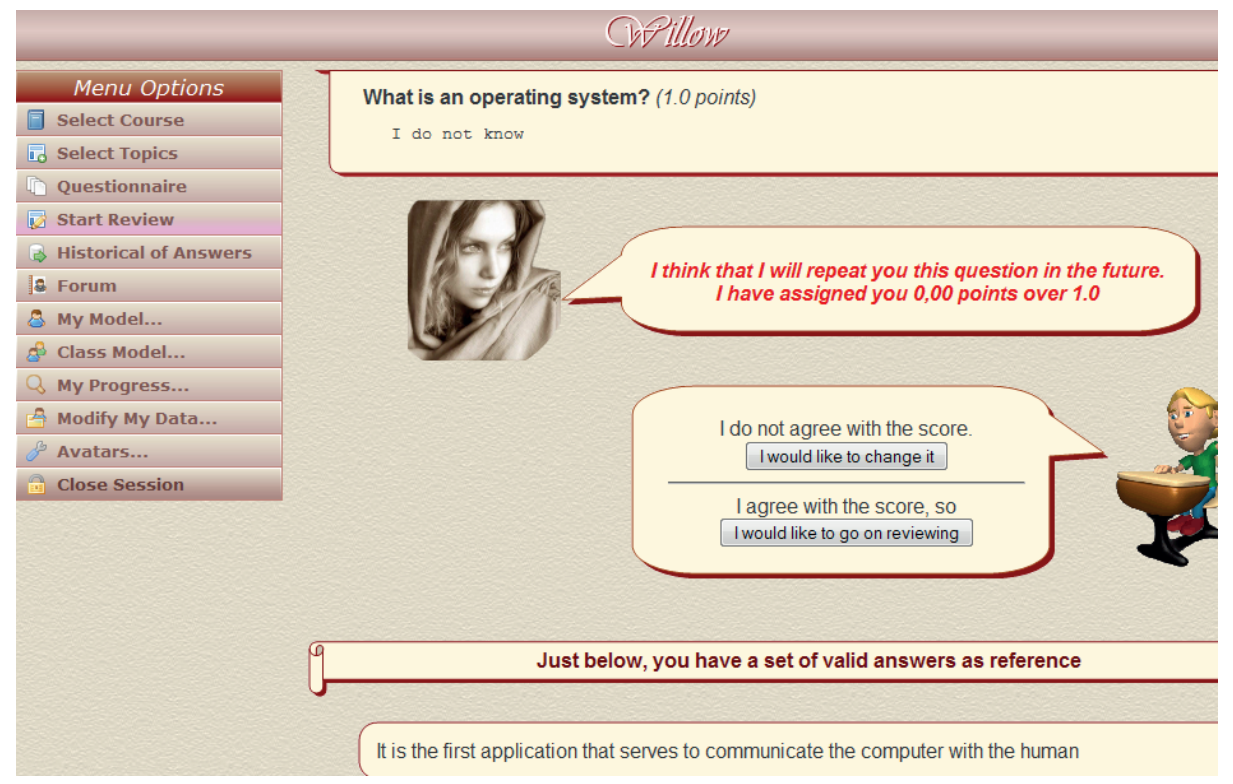

Figure 5.19: Sample feedback webpage of Willow

Moreover, when students fail a question, they do not go directly to the feedback page. Instead, they are encouraged to try to pass the question with the help of a clarification dialogue. The questions in the new dialogue are designed to guide the student towards the correct answer. The first question in this clarification dialogue asks for more information (e.g. in the case where a student has left a blank in the answer space). This new answer is re-evaluated, and where it is found to be correct, the feedback page is shown.

Otherwise, a second clarification question is formulated by asking the student about a key concept related to the answer (e.g. in the case where the student does not know what to say, but maybe knows something about the related concept). The answer is evaluated again, and, if correct, the feedback is shown.

Finally, if the student has not correctly answered the second clarification question, then a third clarification question is formulated by asking the student a true/false 
question. From this last question, the next page is always the feedback page. Failed answers are marked to be asked again in the future.

As soon as the students start answering questions in the system, Willow is able to keep track not only of the difficulty of the questions that each student is able to pass/fail, but also of the use of the key concepts of the course in a student's answers. Further, it can generate and update a conceptual model for each student. That is, a graph in which each node is a concept and the links represent the relationships between the concepts.

Each node is associated with a confidence-value on a scale from 0 (no confidence that the student knows the concept represented by the node) up to 10 (complete confidence that the student knows the concept represented by the node) according to a set of internal metrics (Pérez-Marín, 2007). A color code schema is displayed to make a greater visual impact of this information, so that low confidence-values are mapped to red tones, high confidence-values are mapped to green tones, and average values are mapped to yellow-orange tones.

Do it yourself! Write to diana.perez@urjc.es to ask for an account to log into Willow and interact with the agent. Finally, check your conceptual model and the class conceptual model. Write your opinion and views on the book's website, you can also check what other students have said!

Now you have experienced using an agent as a student, it is time to use the agent as a teacher. The information requested to create a course in Willow should be completed in a template, as shown in Figure 5.20. The idea is to follow the structure of each course. The minimum is to create one lesson with one question and one answer. However, ideally each lesson should have 5 different questions, and each question 2-3 different answers to capture potentially correct answers written by the students.

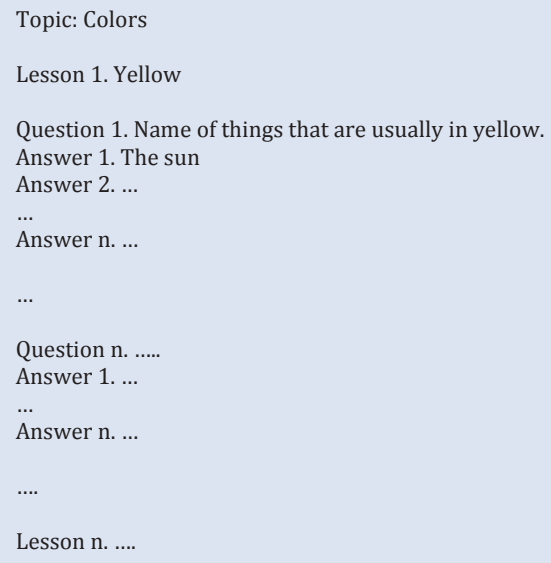

Figure 5.20: Template to create a course in Willow 
It is possible to reuse previous materials (i.e. previous exams) because the template is written in plain text. As can be seen, for each question, the instructor needs to type the statement, and at least one correct answer. It is possible to type more than one correct answer, and Willow compares the answer provided by the student to each one of the answers provided by the instructor. This is a good option to foster lexical variability and to avoid limiting the answer to just one correct version.

Moreover, it is possible to mark a word, or a set of words, as key concepts of the course. That way, Willow can keep track of the use of these words in the student answer to create the conceptual model, which is shown to both the instructor and the student as global feedback of how well the key concepts of the course are being understood at each point.

At any time, teachers are allowed to modify the questions in each course for the agent. This may be necessary if the instructors discover that some questions are too difficult or too easy, or because they find out that they need to add or delete certain key concepts for the conceptual model. Willow is also able to provide guidance to the students. For instance, the agent can automatically send e-mails to students who have not logged into the computer system for a certain number of days (Santos et al. 2011).

Do it yourself! Write some questions following the template uploaded on the book's website, then upload them and see how the questions appear in Willow.

\subsection{Taxonomy: How to Choose Which PCA to Use}

Pérez-Marin (2011) proposed the following taxonomy to classify the main features of PCAs. This taxonomy can be used to choose the agent that is most appropriate, depending on what is required for each course. It is also possible to use a different taxonomy, again it depends on the goals you pursue. This taxonomy has ten main criteria: role and attitude, interaction modality, type of animation, affective possibilities, type of virtual character, adaptive-evolution possibilities, ubiquity, domain, language, and age of the target students.

Regarding the first criteria, Role and attitude, you have to choose if you want the agent to work as a teacher, student or companion. Some possibilities are:

1.1 Instructor/Lecturer/Tutor

1.1.1 Authoritarian

1.1.2 Coach

1.2 Student

1.2.1 Individual

1.2.2 Collaborative

1.3 Companion

1.3.1 Peer companion

1.3.2 Emotional assistant

1.3.3 Troublemaker 
Regarding the Interaction modality, it is possible that:

2.1 The agent starts the conversation

2.2 The student starts the conversation

2.3 Mixed (both theagent and the student can start and continue the conversation)

The type of animation can be:

3.1 None

3.2 Graphics

3.3 Graphics and sound

3.4 3D graphics and sound

3.5 Virtual reality

The affective possibilities can be:

4.1 None

4.2 Emotional support

4.3 Empathy

The type of virtual character can be:

5.1 Human shape without animation

5.2 Human shape with animation

5.3 Without human shape

5.4 Human and non human shape without animation

5.5 Human and non human shape with animation

The adaptive-evolution possibilities (i.e. the possibility that the agent adapts its behaviour to each student, and learns how to evolve to interact better depending on previous interaction) can be:

6.1 None

6.2 Adaptive possibilities

6.3 Evolution possibilities

6.4 Adaptive and evolution possibilities

The ubiquity (i.e. the possibility that the agent is not only used on a computer but on other devices too) can be:

7.1 To be used with a computer

7.2 To be used with mobile devices such as smartphones and/or PDAs

The domain (i.e. the knowledge or competences in which the agent involves the student) can be:

8.1 General

8.2 Specific 
The language in which the agent speaks (spoken and / or written), and the age of the target students (i.e. Pre-Primary Education, Primary Education, etc.)

\subsection{Exercises}

Let's do several exercises to practise the content of this chapter. Remember that all exercises are solved at the end of the chapter, but do not read the solutions until you have tried to answer the exercises on your own first! It is also possible that you'll find different answers to these questions; in that case, you can tell us about them on the book's website.

1. Imagine that you want to improve your 6-year old students' narrative story telling skills, which agent would you use?

2. Imagine that you want to improve your 12-year old students' Math skills, which agent would you use?

3. When would you use a troublemaker agent?

4. Imagine that you want to use an agent following the Learning by Teaching paradigm, which agent would you use?

5. Which role is the one that agents following the Learning by Doing paradigm take?

6. Imagine that you want your 2-year old students to start learning some words in English, which agent would you use?

7. Imagine that you want to teach your students that if they make an effort, they will be able to solve the Maths problems, which agent would you use?

8. Imagine that you want to use an agent following the Learning by Explaining paradigm, which agent would you use?

\subsection{Solved Exercises}

1. I would use Sam because it is an agent that asks children to tell him a story, and helps them to improve that skill.

2. I would use Mike's teachable agent so that students can approach Maths as a game and collaborate among themselves to solve the exercises in class. After class, I would recommend that they use Jake \& Jane so that they would feel accompanied when doing their homework.

3. I would use a troublemaker agent in the role of teacher or instructor when I want to test whether the students are answering with something that they really believe, and they are sure of their answer. This can prevent them answering with the first thing they come up with.

4. I would use Betty because students can test whether they have understood the lesson by telling Betty, and if they tell her something wrong, Mr. Davis will teach them how to correct that. 
5. Usually companions.

6. I would use Baldi because they only need to click on the image and they will hear the name pronounced by Baldi.

7. I would use MyPet because with the energy bar they can see that the more they practise, the better the exercises can be solved.

8. I would use the agents of Active World created by Holmes.

\subsection{References}

Arroyo, I.; Woolf, B.; Royer, J. M. \& Tai, M. (2009), Affective Gendered Learning Companions, Artificial Intelligence in Education.

Biswas, G.; Roscoe, R.; H., J. \& Sulcer, B. (2009), Promoting Self-Regulated Learning Skills in Agent-based Learning Environments, Proceedings of the 17th International Conference on Computers in Education.

Chase, C.; Chin, D.; Oppezzo, M. \& Schwartz, D. (2009), Teachable agents and the Protégé effect: Increasing the effort towards learning, Journal of Science Education and Technology 18, 334-352.

Chen, Z.; Liao, C.; Chien, T. \& Chan, T. (2009), Animal Companion Approach to Fostering Students Effort-Making Behaviors, Artificial Intelligence in Education.

Crowley, R.S.; Tseytlin, E. \& Jukic, D. (2005). ReportTutor - An Intelligent Tutoring System that Uses a Natural Language Interface, AMIA Symposium Proceedings.

Ekman, P. (1999), Facial Expressions, New York: John Wiley \& Sons Ltd.

Gallo, J. \& Pérez-Marín, D. (2011), Lingu, un agente que te enseña a analizar frases en castellano, Final Project in Computer Science, Universidad Rey Juan Carlos.

Graesser, A. C.; Jeon, M. \& Dufty, D. (2008), Agent technologies designed to facilitate interactive knowledge construction, Discourse Processes 45, 298-322.

Graham, C.R. (2005). Blended Learning Systems: Definition, Current Trends, and Future Directions, in 'Handbook of Blended Learning: Global Perspectives, local designs', Pfeiffer Publishing, 3-21.

Hays, M.; Lane, C.; Auerbach, D.; Core, M.; Gomboc, D. \& Rosenberg, M. (2009), Feedback Specificity and the Learning of Intercultural Communication Skills, Artificial Intelligence in Education.

Holmes, J. (2007), Designing agents to support learning by explaining, Computers \& Education 48 , 523-547.

Indurkhya, N. \& Damerau, F.J. (2010). Handbook of Natural Language Processing, CRC Press.

Johnson, W.; Rickel, J. \& Lester, J. (2000). Animated Pedagogical Agents: Face-to-Face Interaction in Interactive Learning Environments, Journal of Artificial Intelligence in Education 11, 47-78.

Kelley, J.F. (1984). An iterative design methodology for user-friendly natural language information applications, ACM Transactions on Information Systems, 2, 26-41.

Lester, J.; Converse, S.; Kahler, S.; Barlow, S.; Stone, B. \& Bhogal, R. (1997), The persona effect: affective impact of animated pedagogical agents. Proceedings of the SIGCHI conference on Human factors in computing systems, 366.

Massaro, D.; Ouni, S.and Cohen, M. \& Clark, R. (2005), A multilingual embodied conversational agent, System Sciences.

Mitkov, R. (2003). The Oxford Handbook of Computational Linguistics, Oxford University Press.

Nunes, M.; Dihl, L.; Fraga, L.; Woszezenki, C.; Oliveira, L.; Francisco, D.and Machado, G.; Nogueira, C. \& Notargiacomo, M. (2002), Animated pedagogical agent in the intelligent virtual teaching environment, Interactive Educational Multimedia 4, 53-60. 
Pareto, L.; Haake, M.; Lindstrom, P.; Sjoden, B. \& Gulz, A. (2012), A teachable-agent-based game affording collaboration and competition: evaluating math comprehension and motivation, Education Tech Research Dev 60, 723-751.

Pérez-Marín, D. \& Boza, A. (2013), A Procedure to Create a Pedagogic Conversational Agent in Secondary Physics and Chemistry Education, International Journal of Information and Communication Technology Education.

Pérez-Marín, D. \& Pascual-Nieto, I. (2012), An Exploratory Study on how Children Interact with Pedagogic Conversational Agents, Behaviour \& Information Technology.

Pérez-Marín, D. (2007), Adaptive Computer Assisted Assessment of free-text students answers: an approach to automatically generate students conceptual models, PhD thesis, Escuela Politecnica Superior, Universidad Autónoma de Madrid.

Pérez-Marín, D. (2011), Investigación en Tecnologías de la Información, capítulo Uso de Agentes Conversacionales Pedagógicos en Sistemas de Aprendizaje Hнbrido (B-learning), Dykinson.

Reategui, E.; Polonia, E. \& Roland, L. (2007), The role of animated pedagogical agents in scenariobased language e-learning: a case-study, Conference ICL.

Rickel, J. \& Johnson, W. (1999), Virtual humans for team training in virtual reality, Proceedings of the Ninth International Conference on Artificial Intelligence in Education, 578-585.

Ryokai, K.; Vaucelle, C. \& Cassell, J. (2003), Virtual peers as partners in storytelling and literacy learning, Journal of computer assisted learning 19(2), 195-208.

Santos, O.; Pascual, I.; D.Pérez-Marín \& Boticario, J. (2011), Extending Computer Assisted Assessment systems with Natural Language Processing, User Modelling, and Recommendations based on Human Computer Interaction and Data Mining, International Joint Conference on Artificial Intelligence (IJCAI), 2519-2524.

Segedy, J.; Kinnebrew, J. \& Biswas, G. (2013), The effect of contextualized conversational feedback in a complex open-ended learning environment., Education Tech Research Dev 61, 71-89.

Yee, N. \& Bailenson, J. (2007), The Proteus effect: The effect of transformed self-representation on behavior, Human Communication Research 33(3), 271.

Zhou, L. (2007), Natural language interface for information management on mobile devices, Behavior \& Information Technology, 26, 197-207. 